\title{
COMPARATIVE STUDY BETWEEN CONVENTIONAL AND DISTAL RADIAL ARTERY APPROACHES FOR CORONARY ANGIOGRAPHY AND/OR INTERVENTION; IMMEDIATE AND SHORT-TERM FOLLOW UP
}

\author{
By
}

\section{Mohamed Ramadan, Mohamed Abd El-Hady and Mansour Sallam}

Cardiology Department, Faculty of Medicine, Al-Azhar University

Corresponding author: Mohamed Sayed Ramadan, Beni-Suef Insurance Hospital, BeniSuef governorate, Egypt

Mobile: +201220083669, E-mail: cardiomoba@gmail.com

\begin{abstract}
Background: Conventional transradial approach (cTRA) gained sound acceptance as an alternative to transfemoral approach (TFA). However, it still having numerous pitfalls as hematoma, spasm and radial artery occlusion. Distal transradial artery access (dTRA) through the anatomical snuffbox emerged as a refined approach to overcome TRA drawbacks.
\end{abstract}

Objectives: To evaluate the feasibility and safety of dTRA for coronary angiography (CAG) and percutaneous coronary intervention (PCI) compared with the cTRA.

Patients and Methods: From February to December 2019, we enrolled 100 consecutive patients who were eligible for CAG plus/minus PCI. The patients were randomized to get their procedure from cTRA (Group I= 50 patients) or from dTRA (Group II= 50 patients). The demographic, technical and post-procedural data were recorded.

Results: In the group II, male gender was predominant $(\mathrm{p}=0.041)$. cTRA group was associated with significantly shorter cannulation time $(\mathrm{p}=0.025)$. The total procedure time was shorter in dTRA, However, it didn't reach statistical significance $(34.2 \pm 25.3$ versus $25.8 \pm 19.7$ minutes, $\mathrm{p}=0.066)$. The procedure success ( $92 \%$ vs $90 \%$ respectively), amount of contrast and radiation exposure, was similar in both groups. The risks of complication events as radial artery spasm, hematoma, or radial artery occlusion were similar in both groups.

Conclusions: Distal radial approach for coronary diagnostic or intervention procedures is a feasible alternative to conventional radial route. dTRA is an attractive access with potential advantages of saving the proximal radial utilization as a graft for bypass surgery or future arteriovenous fistula creation for hemodialysis.

Key words: Conventional radial, distal radial, coronary angiography, local vascular complications.

\section{INTRODUCTION}

As opposed to transfemoral approach (TFA), transradial approach (TRA) has gained a sound acceptance as alternative to TFA mainly because of safety issues especially local vascular complications as well as similar efficacy, better patient satisfaction and shorter hospital stay (Hirzallah et al., 2019 and Mansour et al., 2019). The superiority of TRA over TFA 
was more powered in patients presented with acute coronary syndromes (ACS) (Hamon et al., 2013 and Cantor et al., 2015). However there are many limitations to the traditional / proximal / or conventional TRA (cTRA) performed few millimeters proximal to styloid process of radius as hematoma, radial artery spasm and radial artery occlusion (Mansour et al., 2014 and Aoun et al., 2019).

The distal transradial access (dTRA) in the anatomical snuffbox is a novel technique that was first described in 2017 (Kiemeneij, 2017), as the radial artery has reached the anatomical snuffbox. It has now given rise to superficial palmar branch which contributes in superficial palmar arch from which the digital arteries originate (Wysiadecki et al., 2017). In case of radial artery injury or occlusion, so theoretically dTRA appears safer compared to cTRA. Distal radial access, which is still not recommended by the guidelines, shows a higher success rate and less complication than other sites; therefore, it might be the future for cardiovascular intervention (Zaid et al., 2020).

While the literature provides more than 20 years of data about outcomes with cTRA, dTRA has only been recently investigated in small patient sample studies, with fewer studies evaluating the safety and efficacy of dTRA compared with cTRA.

The purpose of the current study was to evaluate the outcomes of dTRA versus cTRA for coronary angiography and PCI.

\section{PATIENTS AND METHODS}

This was a prospective nonrandomized comparative study included total of 100 patients admitted at our institutes. Patients were enrolled in the study after obtaining their written informed consent and approval of the local ethics committee. Majority of procedures undergone by a single operator who has a robust experience in radial approach with a reasonable proficiency in the distal radial access. The patients divided into two groups; each group enrolled 50 patients. Group I included their procedures undergone from the conventional proximal radial access and the group II from the distal radial access. In case of failure to complete the procedure from the assigned access, the operator had the privilege to crossover to either site to go to ipsilateral ulnar, contralateral radial or femoral accesses.

Inclusion criteria: Patients included in the study were referred for coronary angiography (CAG) plus or minus percutaneous coronary intervention (PCI). Indications for coronary angiography were mainly attributed to chronic coronary syndrome with proved evidence from noninvasive test. Other indications were post revascularization ischemia and assessment of coronary anatomy before valvular surgery.

Exclusion Criteria: Patients with history of prior angiography via radial access, acute coronary syndrome, cardiogenic shock, history of CABG using radial grafts, chronic renal failure, patients with arteriovenous fistula, patients with Peripheral vascular disease (eg, Raynaud disease) or any bone deformity in the arm/forearm. 
Puncture technique: After full explanation to the patients about the procedure and examining the suitability of the target artery, the arm was positioned comfortably for both the patient and operator to ensure puncture success, local infiltration anesthesia was given. A dedicated hydrophilic radial sheathes were used in all patients. The anterior-puncture technique was used in all patients, as the counter-puncture technique isn't suitable for dTRA we unified the technique to adopt only anterior one.

While we obtained a pulsatile blood flow 2-3 cm proximal to the styloid process of the radius in patients enrolled for cTRA, at site of strongest pulsations, we got such pulsatile flow in the anatomical snuffbox at site of strongest pulsations in patients enrolled for dTRA. The patients were asked to grip slightly the thumb under the other four fingers, with the hand slightly abducted to bring the artery more superficial. Because of unfeasibility of ultrasound guidance, one of the valuable tips that we applied was marking of the course of the dTRA before sterilization to facilitate entry during the procedure (Figure 1).

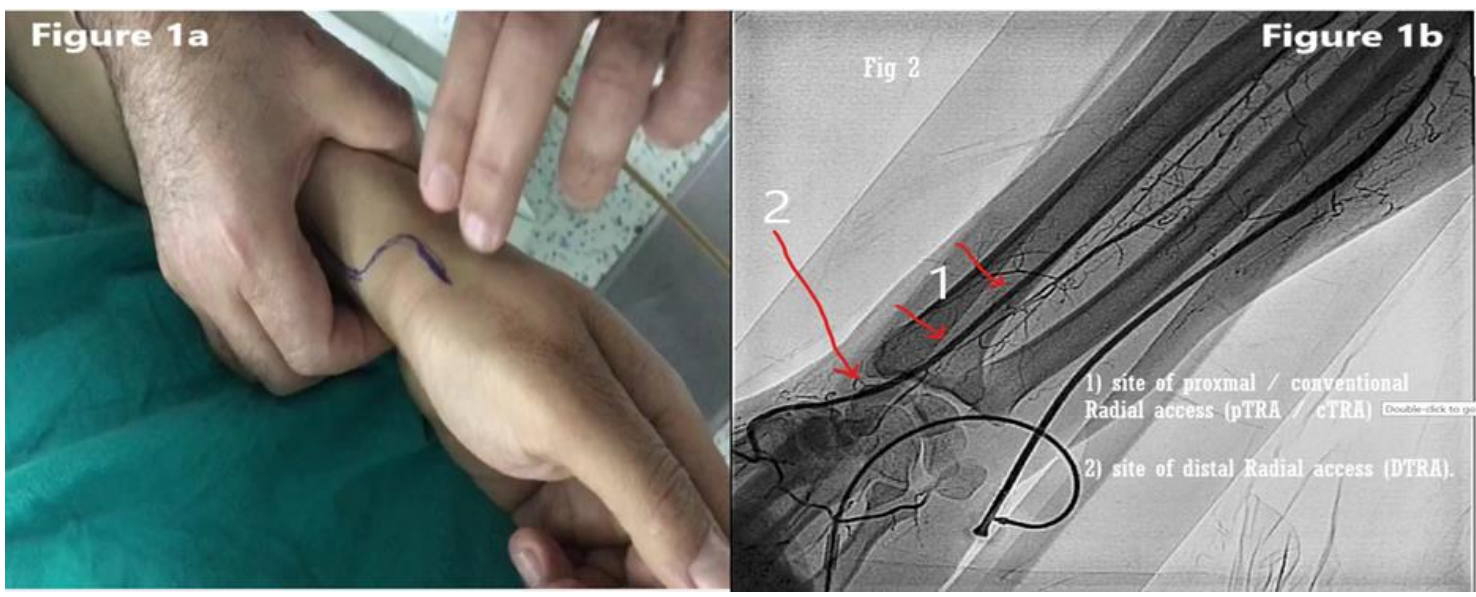

Figure (I): 1a: external marking of the distal radial artery before sterilization based on point of maximal pulse touch. 1b: represents anatomical points of vascular access in both conventional (1) and distal radial (2).

\section{Adjunctive pharmacological therapy:}

After sheath insertion a spasmolytic cocktail (verapamil $2.5 \mathrm{mg}$ mixed with nitroglycerin (100-200 $\mu \mathrm{g})$ given slowly directly into the artery unless contraindicated. Routine 5000 international units of unfractionated heparin were infused into the artery via the radial sheath.

Vascular hemostasis: After the procedure, routine infusion of 50 microgram nitroglycerine were given then the sheath was removed and pressure was held over the arteriotomy site to achieve hemostasis with dedicated transradial bands (TRB) used to seal the vascular puncture site for approximately 150 minutes.

Primary endpoint: The chief primary endpoint of our study was procedural success defined as ability to accomplish the procedure (either diagnostic and or 
intervention) from the assigned puncture site.

Secondary endpoints: We had many secondary objectives (Figure II):

Procedural safety: including incidence of spasm, hematoma and radial artery occlusion.
Procedural outcome: as procedural time, number of attempts to access the artery, radiation exposure and amount of contrast.

Major adverse cardiac events: death, myocardial infarction or stroke.

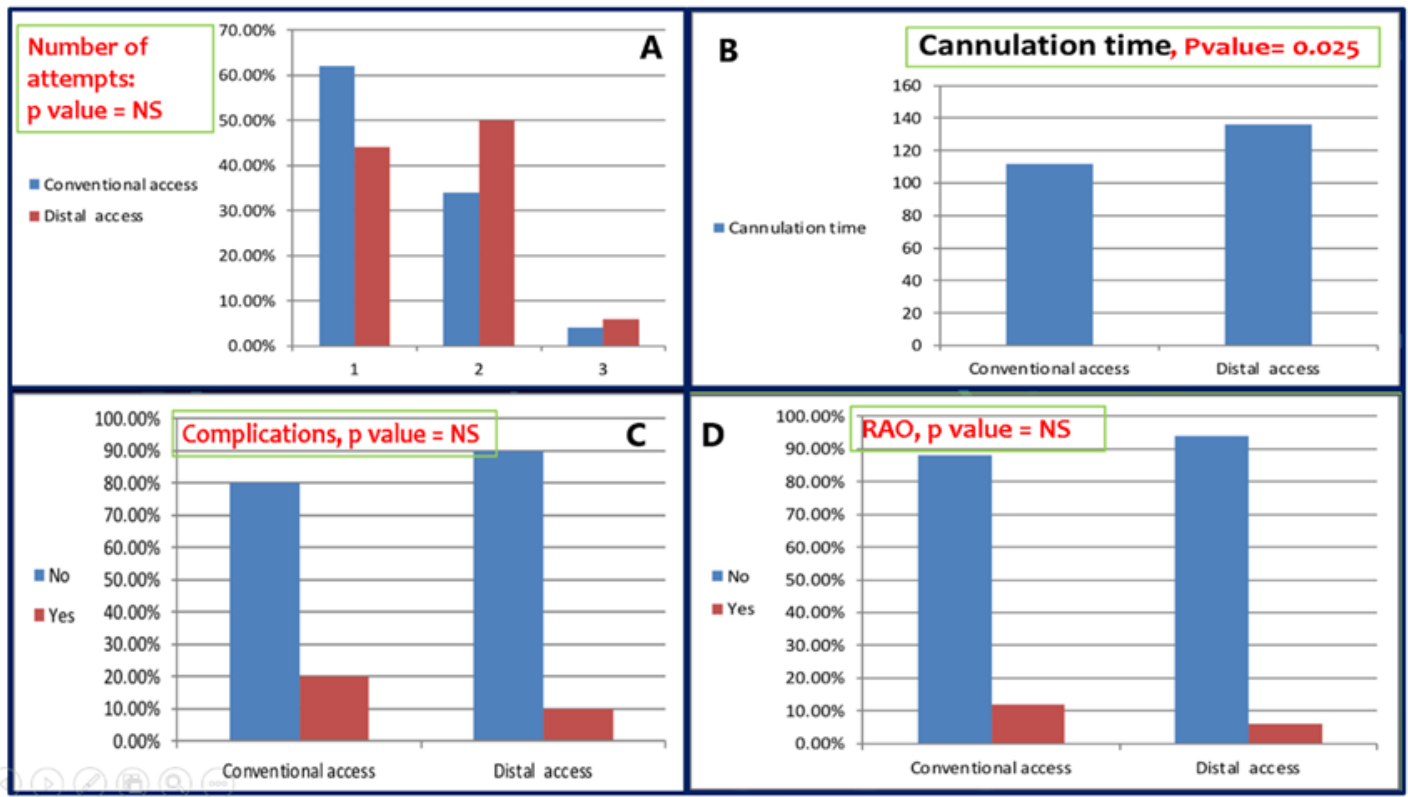

Figure (II): Number of attempts required to get proper back blood flow (A). Cannulation time was significantly shorter in conventional radial access (B). Neither nether total complications frequency $(C)$ nor rates of radial artery occlusion (D) were different in both groups.

\section{Follow-Up:}

- Patients were followed up immediately and three months after the procedure.

- The vessel patency was confirmed by manual palpation and finger pulse oximeter.

- Arterial duplex was done for patients with access site complications specially hematoma and absent radial pulsations.

Statistical analysis: The obtained data were compiled and analyzed using SPSS version 21 (SPSS Inc., Chicago, IL) with statistical significance established at $p \leq$ 0.05 . Continuous variables are presented as means ( \pm standard deviation $[\mathrm{SD}]$ ), and categorical variables are presented using relative frequency distributions and percentages. Time intervals are presented as means $( \pm \mathrm{SD})$. Continuous variables were compared using Student's t-test or the Mann-Whitney test, and categorical data were analyzed using the chi-square test and Yates' continuity correction. Statistical significance established at $\mathrm{p} \leq$ 0.05 . 


\section{RESULTS}

The mean age of the cTRA and dTRA groups were almost identical 54.8 \pm 9.4 and $55.5 \pm 9.3$ years respectively $(\mathrm{p}=0.71)$. The proportion of men was significantly higher in group II $(p=0.041)$. Systemic hypertension was significantly higher in group I ( $\mathrm{p}=0.039)$ with higher incidence of prior myocardial infarction in group II $(\mathrm{p}=0.032)$. (Both groups were statistically comparable with regard to the incidence of diabetes mellitus, dyslipidemia and previous bypass surgery. Also, factors that may affect bleeding and hematoma formation were not different as coagulation profile, anemia and or renal function (Table 1).

Table (1): Baseline criteria among the studied groups

\begin{tabular}{|c|c|c|c|}
\hline Groups & Group I (n=50) & Group II (n=50) & P value \\
\hline Age (years) & $54.8 \pm 9.4$ & $55.5 \pm 9.3$ & 0.71 \\
\hline Male Gender (\%) & 50 & 70 & 0.041 \\
\hline Smoking (\%) & 46 & 58 & 0.23 \\
\hline DM (\%) & 46 & 60 & 0.16 \\
\hline HTN (\%) & 72 & 52 & 0.039 \\
\hline Dyslipidemia (\%) & 60 & 54 & 0.545 \\
\hline Prior MI (\%) & 14 & 32 & 0.032 \\
\hline Prior CABG (\%) & 2 & 12 & 0.117 \\
\hline Prior PCI (\%) & 10 & 20 & 0.161 \\
\hline INR & $1.11 \pm 0.1$ & $1.09 \pm 0.1$ & 0.32 \\
\hline Creatinine & $1.11 \pm 0.8$ & $1.11 \pm 0.2$ & 1 \\
\hline Hb & $11.82 \pm 1.3$ & $11.58 \pm 1.4$ & 0.377 \\
\hline
\end{tabular}

DM: diabetes mellitus. HTN: hypertension. MI: myocardial infarction. CABG: coronary artery bypasses grafting. PCI: percutaneous coronary intervention.

The success rates of cannulation and finishing the procedure from the assigned access site was achieved in $92 \%$ versus 90\% ( $\mathrm{p}=.95)$. Two patients in group I were converted to ipsilateral ulnar and two to contralateral proximal radial, while three patients in group II were converted to proximal ipsilateral TRA and two patients to ipsilateral ulnar. The time required to successfully give local anesthesia, puncture the artery and insert the sheath was significantly shorter in group I as opposed to group II (90(75150) versus $120(90-180), p=0.004)$. The total procedure time, amount of contrast, radiation time and hospital stay were similar between the dTRA and TRA groups (Table 2). 
Table (2): Procedural characteristics of both groups

\begin{tabular}{|c|c|c|c|}
\hline Groups & Group I (n=50) & Group II (n=50) & P value \\
\hline Suriables & $46(92 \%)$ & $45(90 \%)$ & 0.727 \\
\hline Cannulation time in (seconds) & $90(75-150)$ & $120(90-180)$ & 0.004 \\
\hline Number of attempts & $62 \%$ & $44 \%$ & \\
1 & $34 \%$ & $50 \%$ & 0.197 \\
2 & $4 \%$ & $6 \%$ & \\
\hline 3 & $21(12-60)$ & $15(11.5-36.5)$ & 0.155 \\
\hline Procedure time (minutes) & $65(50-200)$ & $52.5(50-150)$ & 0.230 \\
\hline Amount of dye (milliliter) & $1927(815-4010)$ & $1531(788-3279)$ & 0.499 \\
\hline Radiation dose (mGy) & $2(2-6)$ & $2(2-6)$ & $0 . .187$ \\
\hline Time for discharge (hours) & & &
\end{tabular}

The total access site complications were similar in both groups $(20 \%$ versus $10 \%, \mathrm{p}=0.16)$. No radial artery perforation complicated any procedure in both groups, with concomitant low incidence of statistical non-significant difference of forearm hematomas and subsequent radial artery occlusion in both groups. Because of early ambulation especially during COVID-19 pandemic patients' satisfaction was high in both groups with no statistical difference (Table 3 ).

Table (3): Procedural complications and patient satisfaction for both groups

\begin{tabular}{|c|c|c|c|}
\hline Groups & Group I (n=50) & Group II (n=50) & P value \\
\hline Access Site Complications & $10(20 \%)$ & $5(10 \%)$ & 0.161 \\
\hline Hematoma & $3(6 \%)$ & $1(2 \%)$ & 0.61 \\
\hline Perforation or dissection & $0(0 \%)$ & $0(0 \%)$ & ------- \\
\hline Radial Artery Occlusion & $6(12 \%)$ & $3(6 \%)$ & 0.485 \\
\hline Persistent pain & $1(2 \%)$ & $1(2 \%)$ & 1 \\
\hline Patient Satisfaction & $44(88 \%)$ & $46(92 \%)$ & 0.505 \\
\hline
\end{tabular}

\section{DISCUSSION}

The current study represented our early experience in distal radial approach after gaining extensive skill in conventional radial and ulnar access for coronary procedures. In the present study, the dTRA in the snuffbox zone was possible in $90 \%$ of all tries opposed to $92 \%$ in the conventional group with no statistical difference, the success in obtaining the dTRA was fewer compared to what reported by (Roghani-Dehkordi et al., 2018 and Yaowang et al., 2020), in accordance with Ziakas et al. (2020) and better than what had been reported by Yashasvi et al. (2021). The most logic explanation for the relatively lower success rate in dTRA access was our early experience as shown by increasing number of tries to puncture the distal radial artery in the snuffbox. The five failed cases in the dTRA group were in the first half of our study. On every occasion we failed to get the dTRA access, routinely crossed over to the ipsilateral proximal radial access which was successful in two cases, in the other three cases we crossed over to the ipsilateral ulnar artery. 
Because of the natural tapering of the distal vessels, the deep palmar branch of the radial artery at the snuffbox tends to be smaller in size which explains longer time required to get an access as opposed to cTRA $\{136.2 \pm 53.3$ versus $111.7 \pm 54.6$ seconds $(\mathrm{p}=0.025)\}$, our results are consistent with the report of Yashasvi et al. (2021).

The radial access site for coronary angiography is an appealing approach that eliminates the local vascular complications and significantly shortens the hospital stay (Mansour et al., 2019). With revolutionizing a novel technique, we do except better safety, similar efficacy and improved patient satisfaction. The total record of all complications was reported in $20 \%$ and $10 \%$ in cTRA compared to dTRA respectively, however, it didn't reach the statistical significance. The incidence of hematoma was less reported in dTRA group which can be explained by the advantage of the deep palmar branch anatomy of smaller size, more superficial and directly lies onto two bones, so it is easily compressible, our findings are consistent with Yaowang et al. (2020). Moreover, the incidence of radial artery occlusion post procedure was less, also didn't reach the statistical worth.

The dTRA group experienced similar safety profile as compared to cTRA regarding amount of contrast media used, radiation exposure, with no reported cases of death, myocardial infarction or cerebrovascular stroke. Such safety profile together with the similar success and patient satisfaction make the novel access site appealing route for coronary procedures either diagnostic and intervention.
Beside the better safety issues, the hallmark of transradial access over the transfemoral access was the patients' satisfaction attributed to early ambulation. The novel access at the snuffbox maintained such competence as opposed to the conventional radial access. Because of proper and easy hemostasis and early ambulation, early hospital discharge was feasible in both groups with no significant statistical difference.

There are many rewards of left radial over the right radial one mainly because of higher frequency of variant anatomy in the right side as well as similar anatomy to the femoral approach with less radiation exposure (Burzotta et al., 2015 and Rachit et al., 2016). Our practice with the left distal approach was noticeably optimistic in terms of better patients' comfortable protonation position of the left arm extending to the near right groin, comfortable operator position as well as getting the access while working comfortably from the right side and at the meantime gaining the superiority of the left over the right access.

Limitations of the study: The main limitation of the current study is the small sample size as well as the observational, non-randomized design; however, it represents our early experience as well as non-randomized. Another important limit is that the majority of study procedures were performed by one experienced operator in TRA, other procedures performed by less experienced operators that add bias to the final result. Ultrasound was not performed to any patient before puncture to determine the possible small radial artery size or any variant anatomy. These results necessitate larger 
randomized controlled trials for validation.

\section{CONCLUSION}

The current study highlighted the feasibility of the distal radial approach compared to the proximal/conventional radial route with similar efficacy, safety and patient satisfaction. Distal transradial approach is an appealing route for coronary angiography plus or minus intervention, with the refinement of the interventional equipment; it seems dTRA will be the near future access of choice.

\section{REFERENCES}

1. Aoun, J., Hattar L., Dgayli, K., Wong G. and Bhat T. (2019): Update on complications and their management during transradial cardiac catheterization. Expert review of cardiovascular therapy, 17(10):741751.

2. Burzotta F., Brancati, M.F., Porto I., Saffioti S., Aurigemma C., Niccoli G., Leone A.M., Coluccia V., Crea F. and Trani C.(2015): Comparison of right and left upper limb arterial variants in patients undergoing bilateral transradial procedures. Circulation: Cardiovascular Interventions, 8(12):e002863-67.

3. Cantor W.J., Mehta S.R., Yuan F., Džavík V., Worthley M., Niemelä K., Valentin V., Fung A., Cheema A.N., Widimsky P. and Natarajan M. (2015): Radial versus femoral access for elderly patients with acute coronary syndrome undergoing coronary angiography and intervention: insights from the RIVAL trial. American heart journal, 170(5):880-886.
4. Hamon M., Pristipino C., Di Mario C., Nolan J., Ludwig J., Tubaro M., Sabate M., Mauri-Ferré J., Huber $K$., Niemela $K$. and Haude $M$. (2013): Consensus document on the radial approach in percutaneous cardiovascular interventions: position paper by the European Association of Percutaneous Cardiovascular Interventions and Working Groups on Acute Cardiac Care and Thrombosis of the European Society of Cardiology. EuroIntervention, 8(11):1242-1251.

5. Hirzallah H., Amro A., Kusmic D., Curtis Z., Leigh E.C., Numan Y., Parsons J., Amro M., Akpanudo S., Sayyed R. and Elhamdani $M$. (2020): Comparison of transradial and transfemoral approaches for coronary angiography and percutaneous intervention in patients with coronary bypass grafts. Cardiovascular Revascularization Medicine, 21(1):25.

6. Kiemeneij, F. (2017): Left distal transradial access in the anatomical snuffbox for coronary angiography (ldTRA) and interventions (ldTRI). EuroIntervention: journal of EuroPCR in collaboration with the Working Group on Interventional Cardiology of the European Society of Cardiology, 13(7):851-857.

7. Mansour S., Osama T., Suhaib A. and Nasser A. (2019): Challenge to reduce crossover from radial to femoral access for coronary procedures: "RURU" approach: a single center, single operator experience in 1000 procedures. J Cardiovasc Dis Diagn., 7:362-365. 
8. Mansour S., Al-Riyami A., Misbah M., Al-Sukaiti R., Al-Alawi A. and Al-Wahaibi A. (2014): Procedural and clinical utility of transulnar approach for coronary procedures following failure of radial route: Single centre experience. Journal of the Saudi Heart Association, 26(3):138-144.

9. Rachit M. S., Patel D., Abbate A., Cowley M.J. and Jovin I.S.(2016): Comparison of transradial coronary procedures via right radial versus left radial artery approach: A metaanalysis. Catheterization and Cardiovascular Interventions, 88(7):1027-1033.

10. Roghani-Dehkordi F., Hashemifard O., Sadeghi M., Mansouri R., Akbarzadeh M., Dehghani A. and Akbari M. (2018): Distal accesses in the hand (two novel techniques) for percutaneous coronary angiography and intervention. ARYA atherosclerosis, 14(2):95-100.

11. Wysiadecki G., Polguj M., Haladaj R. and Topol M. (2017): Low origin of the radial artery: a case study including a review of literature and proposal of an embryological explanation. Anatomical science international, 92(2):293-298.
12. Yaowang L., Xin S., Ruimian C., Huadong L. and Chen J. (2020): Feasibility and Safety of the Distal Transradial Artery for Coronary Diagnostic or Interventional Catheterization. Journal of Interventional Cardiology, 2020:1-6.

13. Yashasvi C., Kanaparthy N.S., Piplani S., Chugh S., Shroff A., Vidovich M., Nolan J., Mamas M. and Chugh S. K. (2021): Comparison of distal radial access versus standard transradial access in patients with smaller diameter radial Arteries (The distal radial versus transradial access in small transradial Arteries Study: DATA-STAR study). Indian Heart Journal, 73(1):26-34.

14. Zaid N., Jahangir S., Adjepong D. and Malik B. H. (2020): Distal radial artery access: the future of cardiovascular intervention. Cureus, 12(3):e7201-09.

15. Ziakas A., Koutouzis M., Didagelos M., Tsiafoutis I., Kouparanis A., Gossios T., Kontopodis E., Tassopoulos A., Katsanou K., Lazaris E. and Karvounis H. (2020): Right arm distal transradial (snuffbox) access for coronary catheterization: initial experience. Hellenic Journal of Cardiology, 61(2):106-109. 
در اسة مقارنة بين النهج الثرياني الكعبري التقليدي و القاصي لعمل القسطرة التشخيصية مع/أو العلاجية للشر ايين التهين التاجية:

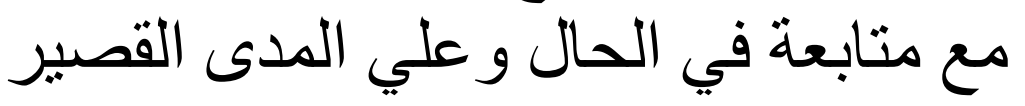

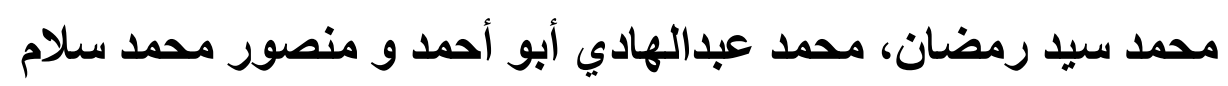
قسم امراض القلب والاوعية الدموية، كلية الطب، جامعة الأزهر محمد سيد رمضان، مستثفي الثأمين الصحي بيني سويف، 01220083669،

E-mail: cardiomoba@gmail.com

خلفية البحث: إج ا رء القسط رة عن طريق الثريان الزندي هي بليل مقترح للمرضي الغير ملانمين الإج ارء القسطرة

عن طريق الثريان الكبري اوج ارء القسطرة التشخيصية والتلاخلية عن طريق الثريان الزندي

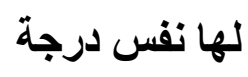
أمان وفاعليه إج ا رئها عن طريق الثريان الكعبري.

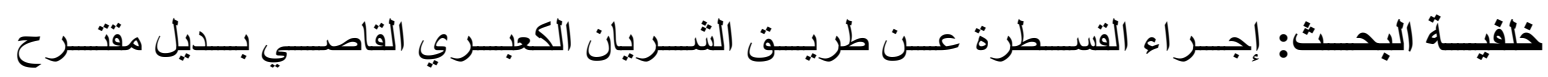

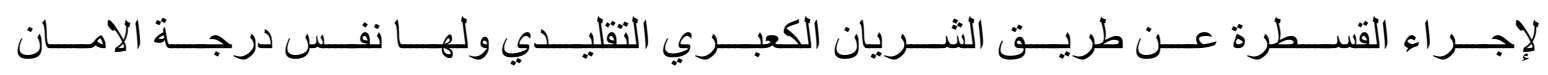

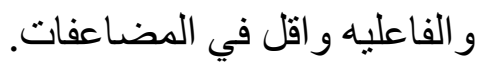

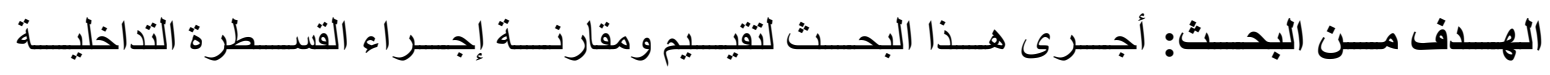

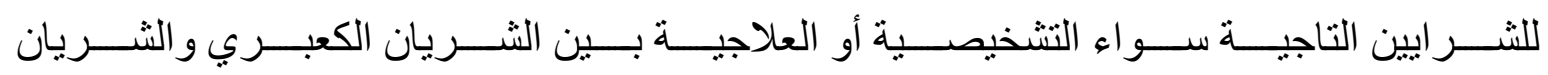

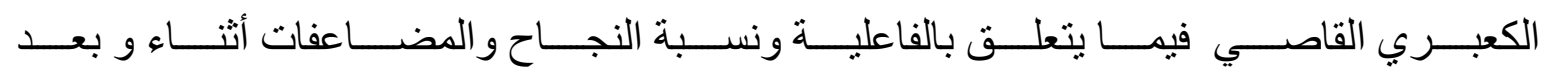

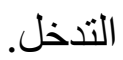

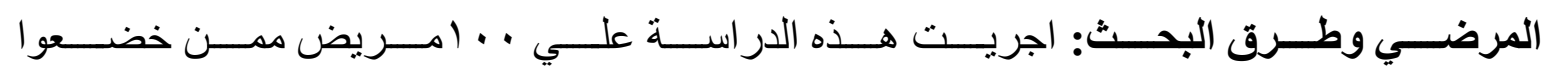

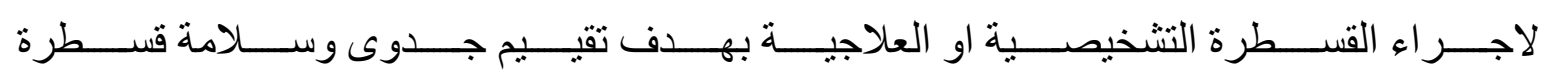

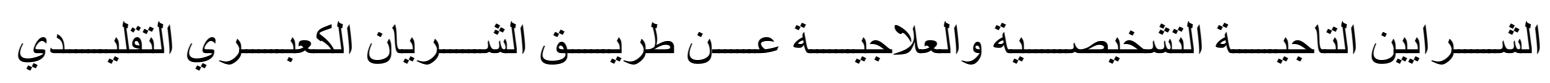

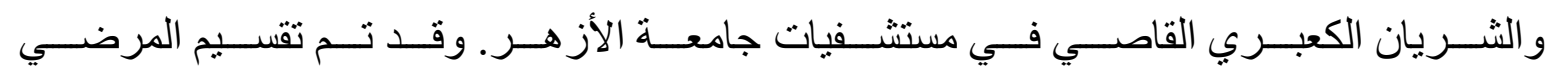

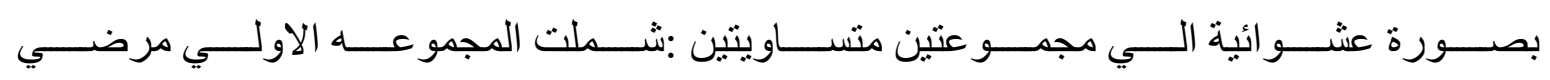




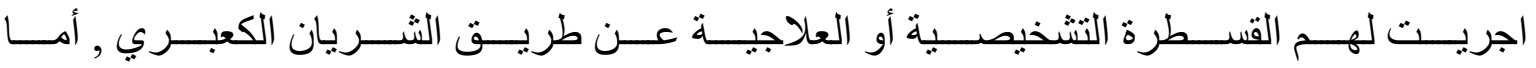

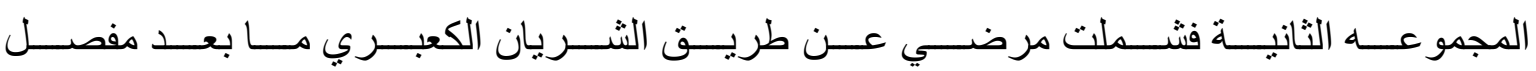

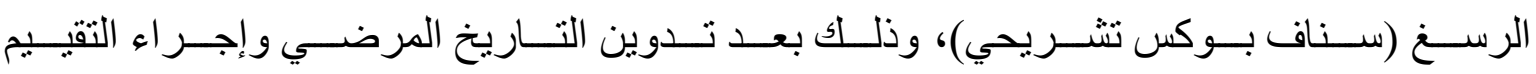
السريري لجميع المرضي.

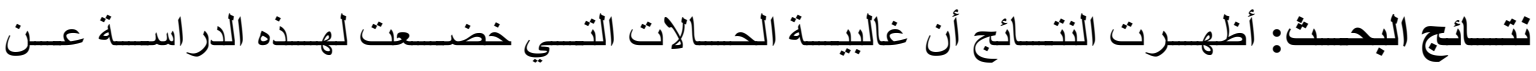

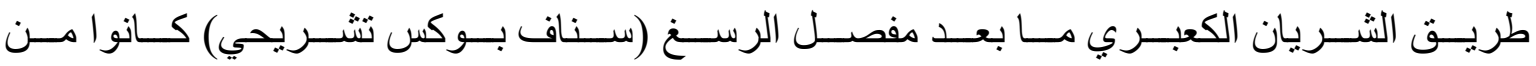

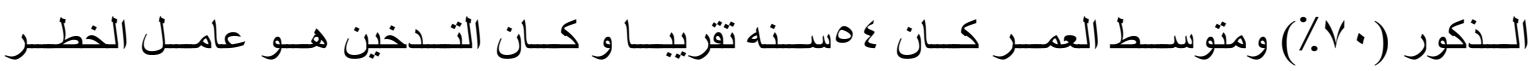

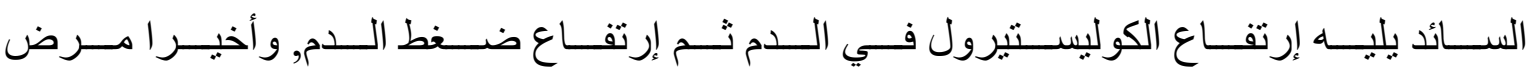
السكري في كلا المجمو عتين.

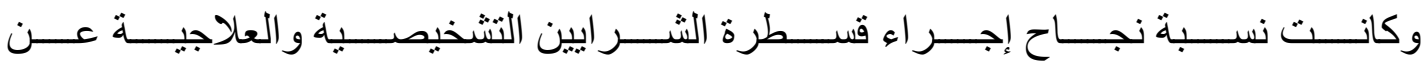

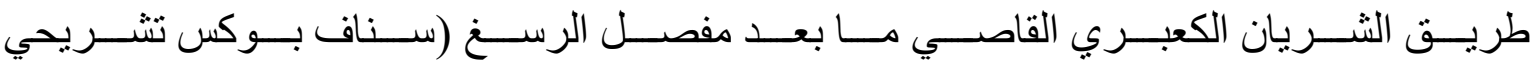

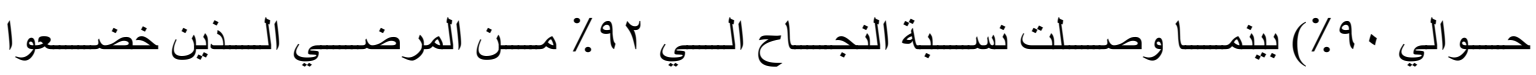
لمثل هذا الاجر اء عن طريق الثريان الكعبري التقليدي.

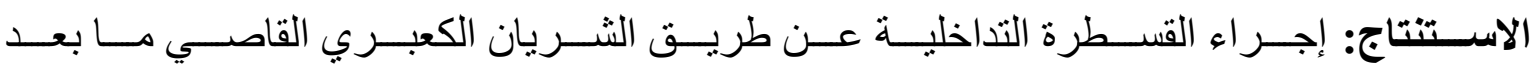

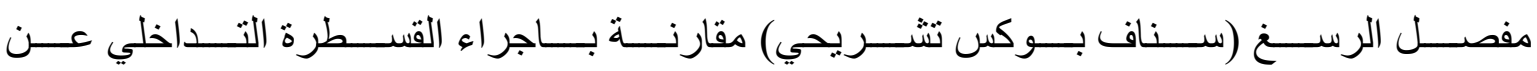

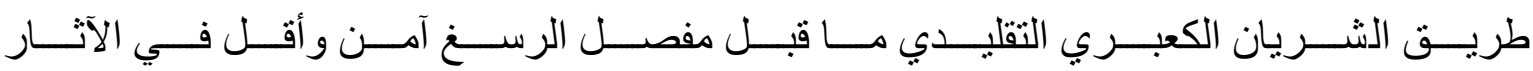

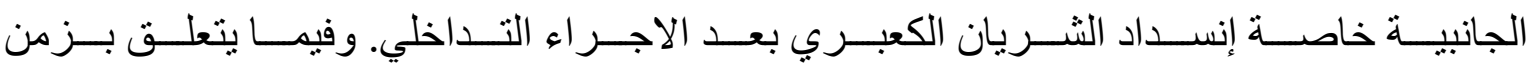

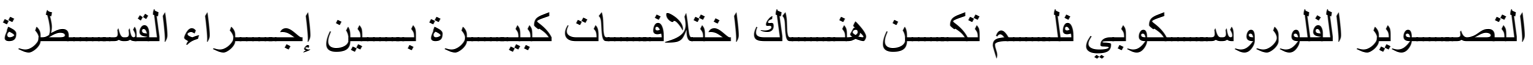

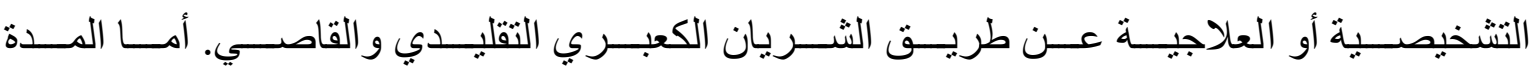

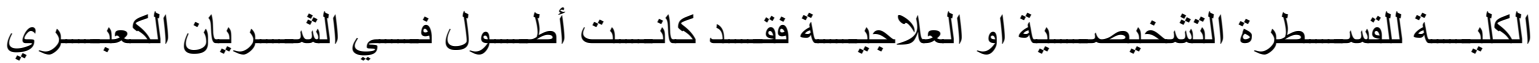
القاصي عنها في الثريان الكعبري التقليدي بصورة لا تمثل قيمة احصائية.

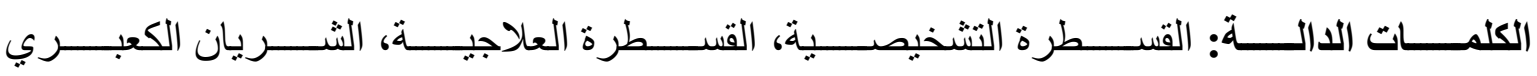
التقليدي، الثريان الكعبري القاصي، مضاعفات الاوعية الدموية. 